\title{
The German ZKBS providing advice for risk mamagers since 1978
}

\author{
H. Pfister \\ Chairman of the "Zentrale Kommission für die Biologische Sicherheit" (ZKBS) \\ Correspondence to: Prof. Dr. Herbert Pfister, Institute of Virology, University of Cologne, \\ Fürst Pückler Strasse 56, D-50935 Köln, Germany, E-mail: herbert.pfister@medizin.uni-koeln.de
}

The German Central Commission on Biological Safety (ZKBS) is a body of honorary experts, examining genetically modified organisms (GMOs) for possible risks to humans and the environment and is responsible for issuing statements to this end. Statements of the ZKBS constitute recommendations that should be taken into consideration. Any deviation from the recommendations of the ZKBS requires justifying explanations. The office of the ZKBS is in the BVL (Federal Office of Comsumer Protection and Food Safety).

Its duties comprise the assessments of the safety of genetic engineering operations and facilities as well as the assessments of the safety of deliberate release into the environment including placing on the market of GMO. With the amendment of the Genetic Engineering Act in April 2008, the number of experts was raised to twenty members and twenty deputy members representing different scientific fields and public interests.

The commission adopts its resolutions either in written proceedings or in closed sessions that are held approximately once in every two months at the BVL, to which the involved authorities and the Federal Ministries are invited. A report of activities is published each year, for the purpose of informing the public.

To access this journal online:

http://www.birkhauser.ch/JVL 